\title{
Roles of renin-angiotensin system and Wnt pathway in aging-related phenotypes
}

Takehiro Kamo ${ }^{1}$, Hiroshi Akazawa ${ }^{1,3^{*}}$, Jun-ichi Suzuki ${ }^{2}$ and Issei Komuro ${ }^{1,3}$

\begin{abstract}
The renin-angiotensin system (RAS) regulates diverse cellular responses and is crucial for normal organ development and function. On the other hand, RAS exerts deleterious effects promoting cardiovascular and multiple organ damage and contributes to promoting various aging-related diseases and aging-related decline in multiple organ functions. RAS blockade has been shown to prevent the progression of aging-related phenotypes and promote longevity. Wnt signaling pathway also plays a major role in the regulation of mammalian pathophysiology and is essential for organismal survival, and furthermore, it is substantially involved in the promotion of aging process. In this way, both RAS signaling and Wnt signaling have the functions of antagonistic pleiotropy during the process of growth and aging. Our recent study has demonstrated that an anti-aging effect of RAS blockade is associated with down-regulation of canonical Wnt signaling pathway, providing evidence for the hierarchical relationship between RAS signaling and Wnt signaling in promoting aging-related phenotypes. Here, we review how RAS signaling and Wnt signaling regulate the aging process and promote aging-related diseases.
\end{abstract}

Keywords: AT, receptor, ARB, Cardiovascular disease, Complement C1q, Skeletal muscle regeneration

\section{Background}

The renin-angiotensin system (RAS) plays pleiotropic roles in regulating mammalian pathophysiology. Angiotensin II (Ang II) is a key molecule of RAS and is produced as a result of sequential cleavage of angiotensinogen by renin and angiotensin-converting enzyme (ACE). Ang II exerts diverse pathophysiological effects on binding to Ang II type $1\left(\mathrm{AT}_{1}\right)$ receptor [1]. $\mathrm{AT}_{1}$ receptor is a well-known member of the $G$ proteincoupled receptor family, which shares the structure characterized by seven transmembrane-spanning $\alpha$ helices. Mice have two $\mathrm{AT}_{1}$ receptor isoforms $\left(\mathrm{AT}_{1 \mathrm{a}}\right.$ and $\mathrm{AT}_{1 \mathrm{~b}}$ ) which are encoded by separate genes (Agtrla and Agtr1b), whereas humans have a single $\mathrm{AT}_{1}$ receptor isoform encoded by AGTR1 gene. Mouse Agtr1a gene is a homolog to human AGTR1 gene, and $\mathrm{AT}_{1 \mathrm{a}}$ receptor is the major $\mathrm{AT}_{1}$ receptor isoform in mice. $\mathrm{AT}_{1}$ receptor is activated by binding of Ang II or by mechanical stretch in the absence of Ang II [2, 3].

\footnotetext{
*Correspondence: akazawah-tky@umin.ac.jp

'Department of Cardiovascular Medicine, Graduate School of Medicine, The University of Tokyo, 7-3-1 Hongo, Bunkyo-ku, Tokyo 113-8655, Japan

${ }^{3}$ AMED-CREST, Japan Agency for Medical Research and Development,

Chiyoda-ku, Tokyo 100-0004, Japan

Full list of author information is available at the end of the article
}

A decrease in extracellular volume caused by fluid loss or low salt intake stimulates secretion of renin, which leads to production of Ang II and thereby induces systemic vasoconstriction, salt and water retention, and sympathetic nervous activation. These responses restore blood pressure and electrolyte and water balance. In addition to regulation of hemodynamic homeostasis, RAS is essential for normal organ development. Mice deficient in angiotensinogen [4] or in both $\mathrm{AT}_{1 \mathrm{a}}$ and $\mathrm{AT}_{1 \mathrm{~b}}$ receptor isoforms $[5,6]$ showed abnormal phenotypes in the kidney. The administration of ACE inhibitors or $\mathrm{AT}_{1}$ receptor blockers (ARBs) is contraindicated during pregnancy due to an increased risk of fetal disorders [7]. Thus, RAS is crucial for both embryogenesis and maintaining homeostasis and apparently beneficial for survival.

On the other hand, RAS has detrimental effects on cardiovascular tissues. $\mathrm{AT}_{1}$ receptor activation evokes diverse $G$ protein-dependent and $G$ protein-independent signaling pathways, leading to cell proliferation, hypertrophic responses, apoptosis, generation of reactive oxygen species (ROS), and tissue inflammation [8]. RAS has been shown to promote the pathophysiological processes of various aging-related disorders, including not only 
cardiovascular diseases and heart failure but also diabetes, chronic kidney disease, dementia, osteoporosis, and cancer [9]. Recent studies have demonstrated that inhibition of RAS prolongs the physiological aging process and promotes longevity in rodents [10], suggesting the involvement of RAS in the aging process per se.

In addition to $\mathrm{AT}_{1}$ receptor, Ang II type $2\left(\mathrm{AT}_{2}\right)$ receptor is also a functional receptor with high affinity for Ang II [1]. $\mathrm{AT}_{2}$ receptor activation has vasodilatory, anti-proliferative, and anti-inflammatory effects, which counteract the effects of $\mathrm{AT}_{1}$ receptor signaling [1]. Thus, $\mathrm{AT}_{2}$ receptor signaling may provide cardiovascular protection and possibly prevent the progression of aging-related diseases. Ang II is cleaved by ACE2 to form another peptide Ang (1-7). This ACE2-Ang (1-7) axis, acting via another $\mathrm{G}$ protein-coupled receptor Mas, is also involved in vasodilatory, anti-fibrotic, and antiinflammatory properties [11]. While the ACE-Ang II$\mathrm{AT}_{1}$ receptor axis has been extensively studied, research on the role of ACE2-Ang (1-7)-Mas receptor axis in the aging process has been limited.

Wnt signaling pathway also regulates diverse cellular responses during embryogenesis and is required for normal development and function of organs [12]. On the other hand, canonical Wnt/ $\beta$-catenin signaling is also involved in the aging process and promotes aging-related phenotypes [13, 14]. Accordingly, both RAS and Wnt signaling pathway have antagonistic and pleiotropic effects in the physiological process of growth and aging because they are essential and beneficial early in life but deleterious later in life [9].

We have recently reported that RAS blockade prevented the aging-related functional decline in skeletal muscle and that this anti-aging effect of RAS blockade was associated with down-regulation of $\mathrm{Wnt} / \beta$-catenin signaling pathway [15]. These findings suggest the relationship between RAS signaling and Wnt/ $\beta$-catenin signaling in promoting aging-related phenotypes. This review focuses on how RAS and Wnt signaling pathway regulate the aging process and how they play roles as possible targets for preventing and treating aging-related diseases.

\section{RAS in aging-related cardiovascular diseases and heart failure}

Aging is usually defined as a progressive loss of multiple organ functions with advancing age. It is regulated by a wide variety of factors including genetic backgrounds and environmental stresses. Aging increases the risks of various cardiovascular diseases, such as hypertension, atherosclerotic vascular disease, cardiac remodeling, and congestive heart failure. RAS is widely recognized as a key factor contributing to the pathogenesis throughout the "cardiovascular continuum" [16].

RAS plays a fundamental role in the pathogenesis of hypertension even at an early stage. Sustained and excessive activation of RAS signaling induces continuous vasoconstriction and promotes vascular hypertrophy and endothelial dysfunction by direct as well as indirect hemodynamic effects, thereby contributing to the accelerated rise of blood pressure [17]. Indeed, the administration of an ARB reduced the development of hypertension in prehypertensive patients [18]. RAS blockade leads to a better outcome on survival in high-risk animals with hypertension. The treatment with an ACE inhibitor or ARB doubled the life span of stroke-prone spontaneously hypertensive rats to 30 months, which was comparable to that of normotensive rats $[19,20]$. This life extension effect was associated with preservation of cardiac function as well as endothelial function by the treatment with an ACE inhibitor or ARB [19, 20].

RAS contributes to the promotion of atherosclerotic process. Ang II stimulates activity of nicotinamide adenine dinucleotide/nicotinamide adenine dinucleotide phosphate $(\mathrm{NAD}(\mathrm{P}) \mathrm{H})$ oxidase which increased ROS formation [21]. Ang II also stimulates the release of proinflammatory cytokines and promotes the recruitment of macrophages and $\mathrm{T}$ cells through the generation of adhesion molecules and chemokines [22]. This increased oxidative stress and proinflammatory state leads to the development of endothelial dysfunction and vascular remodeling [23]. Furthermore, RAS promotes vasoconstriction, alters the composition of extracellular matrix, and enhances migration and proliferation of vascular smooth muscle cells [24]. Thus, RAS induces diverse cellular responses within the vascular wall, leading to the progression of atherosclerotic cascade.

Persistent and excessive activation of RAS plays a substantial role in pathological cardiac hypertrophy and cardiac remodeling. $\mathrm{AT}_{1}$ receptor activation induces hypertrophic responses in cardiomyocytes and extracellular matrix protein synthesis in cardiac fibroblasts [25]. Ang II infusion induced cardiac hypertrophy independently of blood pressure elevation in rats [26], and cardiac-specific overexpression of $\mathrm{AT}_{1}$ receptor induced cardiac hypertrophy, interstitial fibrosis, and contractile dysfunction in mice [27, 28]. RAS blockade is highly effective in preventing the progression of cardiac remodeling and heart failure. $\mathrm{AT}_{1 \mathrm{a}}$ receptor-deficient mice showed less severe cardiac dysfunction induced by myocardial infarction [29], administration of cardiotoxic agent doxorubicin [30], or genetic disruption of muscle LIM protein (MLP) [31]. A meta-analysis demonstrated that ARBs were the most effective among antihypertensive drugs for reducing left ventricular mass in patients 
with essential hypertension [32]. In addition, clinical trials have demonstrated that ACE inhibitors or ARBs reduce death and hospitalization in the broad spectrum of patients with heart failure [33].

\section{RAS in other aging-related diseases}

It has been demonstrated that RAS is involved in the pathophysiological processes of other aging-related disorders, such as diabetes, chronic kidney disease, dementia, osteoporosis, and cancer [9].

RAS contributes to the pathogenesis of insulin resistance, a notable feature of metabolic syndrome and type 2 diabetes mellitus [34]. Ang II-mediated activation of $\mathrm{AT}_{1}$ receptor modulates the effects of insulin signaling [35]. For example, $\mathrm{AT}_{1}$ receptor activation synergistically promotes the proliferative effects of insulin but inhibits its metabolic actions. Also, the direct effect of Ang II on islet contributes to impaired $\beta$ cell function. Acute infusion of Ang II inhibited the early phase of insulin secretion in rats [36], and RAS blockade improved islet morphology and prevented islet fibrosis in diabetic rats [37]. Recent clinical trials have demonstrated that RAS blockade improves insulin sensitivity and reduces the incident risk of diabetes in high-risk patients [38].

RAS signaling plays a major role in promoting chronic kidney disease. Ang II induces vasoconstriction of the post-glomerular arterioles and increases the glomerular hydrostatic pressure and the ultrafiltration of plasma proteins, thereby contributing to the onset and progression of chronic renal damage [39]. In addition to hemodynamic effects, Ang II exerts non-hemodynamic effects promoting renal tissue injury, through increased generation of ROS, up-regulation of cytokines and adhesion molecules, activation and recruitment of macrophages, and increased synthesis of extracellular matrix proteins [40]. RAS inhibitors provide renal protection and reduce proteinuria and decline of glomerular filtration rate in patients with chronic kidney disease [41, 42].

Recent studies unraveled the possible involvement of RAS in neuropathology of Alzheimer's disease or bone metabolism. ARB treatment decreased the accumulation of $\beta$-amyloid proteins in the brain and attenuated the development of cognitive impairment in a mouse model of Alzheimer's disease [43]. In ovariectomized rats with hypertension, ARB treatment attenuated osteoporosis and suppressed an increase in osteoclast activity [44]. Clinical studies have suggested that antihypertensive treatment with ACE inhibitors was associated with high bone mineral density and reduced the risk of bone fractures [45].

Furthermore, RAS is associated with cancer-related signaling pathways. $\mathrm{AT}_{1}$ receptor is expressed in several human cancer cell lines including pancreatic and prostate cancer cell lines $[46,47]$ and in a subpopulation of
$E R$-positive, ERBB2-negative breast cancer cases [48], and $\mathrm{ARB}$ treatment suppressed $\mathrm{AT}_{1}$ receptor-positive cancer cell proliferation and tumor growth. The growth of tumor cells engrafted in $\mathrm{AT}_{1 \mathrm{a}}$ receptor-deficient mice was reduced, accompanied by reduction in tumor-related angiogenesis [49]. Ang II induced the proliferation of myeloid progenitor cells in the spleen in a mouse model of lung adenocarcinoma, thereby supplying tumor-associated macrophages to promote tumor development [50]. These findings indicate that RAS signaling plays an important role in tumor growth and progression through inducing tumor cell proliferation, tumor-associated angiogenesis, and tumor-associated macrophage expansion.

\section{RAS in physiological aging process}

RAS blockade has been shown to suppress the deleterious effects during the physiological aging process in rodents. The administration of an ACE inhibitor or ARB to CF1 mice or Wistar rats led to a prolongation of life span, which was associated with a decrease in cardiac and renal fibrosis [51, 52]. CF1 mice treated with enalapril, but not with propranolol, nifedipine, or hydrochlorothiazide, revealed protection from organ damage associated with aging and prolonged life span, even though these drugs induced similar hypotensive effects [53]. Therefore, RAS inhibitor regulates life span independently of blood pressure-lowering effect. $\mathrm{AT}_{1 \mathrm{a}}$ receptor-deficient mice also exhibited a prolongation of life span, which was accompanied by less cardiac hypertrophy and fibrosis [10]. The accumulation of oxidative stress caused by ROS substantially contributes to the aging process [54]. The treatment with an ACE inhibitor was associated with a decrease in apoptosis and the suppression of aging-related decrease in mitochondrial number and mitochondrial superoxide dismutase in murine cardiomyocytes $[51,55] . \mathrm{AT}_{1 \mathrm{a}}$ receptordeficient mice showed less oxidative damage in the heart and kidney and prevention of aging-related loss of mitochondria in the kidney [10]. In addition, genetic disruption of $\mathrm{AT}_{1 \mathrm{a}}$ receptor induced an increase in expression levels of Nampt and Sirt3 in the kidneys of aging mice [10]. In a nutrient-deprived environment, increased expression of Nampt leads to the accumulation of its biosynthetic product nicotinamide adenine dinucleotide $\left(\mathrm{NAD}^{+}\right)$in mitochondria, which in turn activates mitochondrial sirtuin 3 (SIRT3) [56]. SIRT3 is a $\mathrm{NAD}^{+}$-dependent deacetylase that protects against stress-mediated cell death. These findings demonstrate that inhibition of RAS promotes longevity, possibly through attenuation of oxidative stress and up-regulation of prosurvival genes.

We have recently reported that $\mathrm{AT}_{1 \mathrm{a}}$ receptor-deficient mice showed less severe aging-related phenotypes in other tissues as well, such as functional decline in skeletal muscle [15]. RAS blockade can prevent aging-related sarcopenia. It has been demonstrated that elderly persons 
with hypertension taking ACE inhibitors had lower decline in muscle strength and larger muscle mass of the lower extremities than users of other antihypertensive drugs $[57,58]$. In aged mice, ARB treatment protected against disuse atrophy of skeletal muscle [59]. One of the hallmarks of aging is a decline in the regenerative capacity of skeletal muscle following injury. ARB treatment led to histological improvement in skeletal muscle regeneration after laceration in mice [60]. ARB inhibited transforming growth factor- $\beta$ (TGF- $\beta$ ) signaling and thereby attenuated TGF- $\beta$-mediated impairment of muscle regeneration in mice with myopathy [61]. In addition, Ang II may have direct anti-proliferative effects on satellite cells, which are crucial for skeletal muscle growth and regeneration, via $\mathrm{AT}_{1}$ receptor [62]. We have shown that treatment with an ARB restored skeletal muscle function assessed by treadmill test after cryoinjury in mice [15]. ARB-treated mice showed an increase in satellite cell population, enhanced regeneration of myofibers, and decreased fibrosis in cryoinjured skeletal muscle. Taken together, RAS can be targeted to protect against deleterious effects associated with aging process and promote longevity.

\section{Relationship between RAS and Wnt signaling in aging}

Wnt proteins initiate signaling cascade on binding to Frizzled receptor and low-density lipoprotein receptorrelated protein (LRP) 5/6 coreceptor, which leads to stabilization of cytosolic $\beta$-catenin $[12,63]$. Then, translocating to nucleus, $\beta$-catenin activates target gene transcription. It has been demonstrated that canonical Wnt/ $\beta$-catenin signaling is also involved in the aging process. Wnt/ $\beta$-catenin signaling activity was enhanced in multiple tissues of a klotho-deficient mouse model of accelerated aging [64]. Wnt treatment attenuated skeletal muscle regeneration in young mice, and inhibition of canonical Wnt signaling restored the impairment of muscle regeneration in aged mice [13]. Moreover, Wnt/ $\beta$-catenin signaling was augmented in skeletal muscle satellite cells exposed to the serum of aged mice, indicating that components of aged serum contributed to the agingrelated activation of Wnt signaling [13]. Complement $\mathrm{C} 1 \mathrm{q}$ has recently been identified as an activator of Wnt/ß-catenin signaling independently of Wnt [14]. C1q activates canonical Wnt/ $\beta$-catenin signaling through binding to Frizzled receptor and inducing $\mathrm{C} 1 \mathrm{~s}$-dependent cleavage of LRP6 coreceptor. Macrophages are major cells that secrete $\mathrm{C} 1 \mathrm{q}$ [65]. Aging mice have increased serum and tissue levels of $\mathrm{C} 1 \mathrm{q}$ and enhanced Wnt signaling activity [14]. C1q treatment stimulated fibroblast proliferation and collagen synthesis but suppressed satellite cell proliferation in skeletal muscle, and promoted agingrelated impairment of skeletal muscle regeneration through activation of Wnt/ $\beta$-catenin signaling [14]. C1q was secreted from macrophages recruited to the aorta in Ang II-infused mice, and C1q-mediated activation of Wnt/ $\beta$-catenin signaling induced proliferation of vascular smooth muscle cells and promoted arterial remodeling [66].

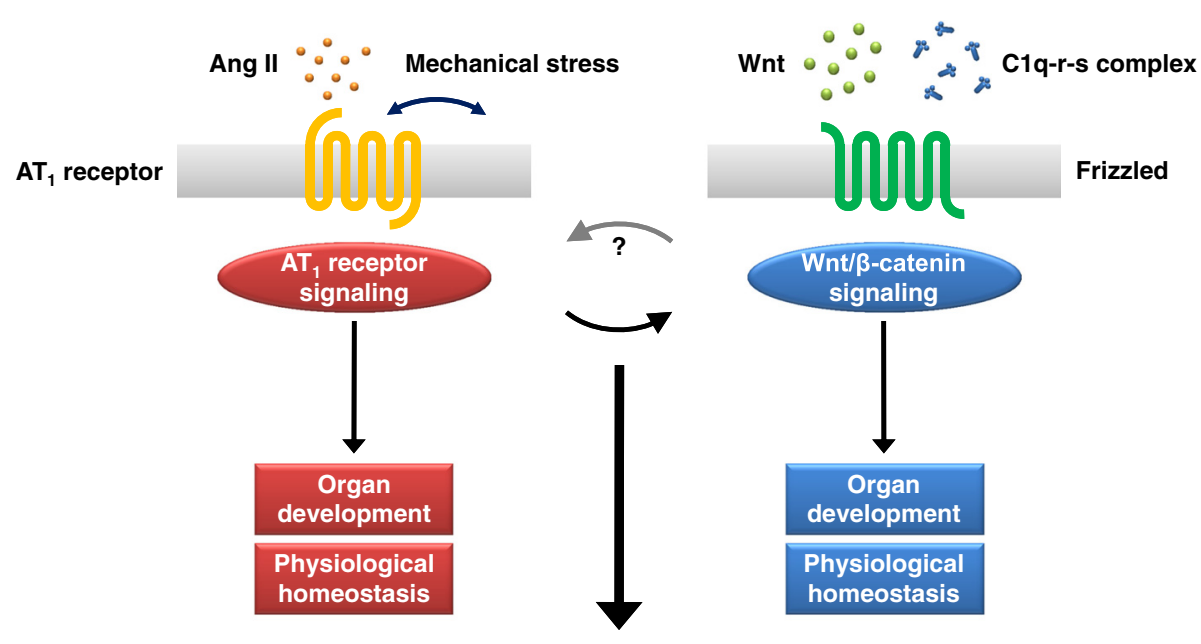

Aging-related phenotypes

Fig. 1 RAS signaling and Wnt signaling in aging process. AT, receptor is activated upon stimulation by binding of Ang II or mechanical stress, and Wnt/B-catenin signaling cascade is initiated by binding of Wnt proteins or C1q-r-s complex to Frizzled receptor. Both $\mathrm{AT}_{1}$ receptor signaling and $\mathrm{Wnt} / \beta$-catenin signaling are essential for normal organ development and crucial for regulation of physiological homeostasis. On the other hand, $\mathrm{AT}_{1}$ receptor signaling and $\mathrm{Wnt} / \beta$-catenin signaling are involved in the aging process, and they are hierarchically related in promoting aging-related phenotypes. $\mathrm{AT}_{1}$ receptor blockade protects against aging-related deleterious effects through down-regulation of aging-promoting C1q-Wnt/ß-catenin signaling pathway 
We have demonstrated that serum $\mathrm{Clq}$ concentration was increased, and $\mathrm{C} 1 \mathrm{q}$ expression and $\mathrm{Wnt} / \beta$-catenin signaling activity in skeletal muscle were augmented after cryoinjury in mice, but ARB treatment inhibited both the increase in serum $\mathrm{Clq}$ level and the activation of C1qWnt/B-catenin signaling in injured muscle [15]. C1q expression in macrophages was reduced by administration of ARB both in culture and in injured muscle. Moreover, these beneficial effects of ARB on skeletal muscle repair after injury were reversed by topical administration of C1q [15]. These findings suggest that RAS blockade prevents aging-related phenotypes through down-regulation of aging-promoting $\mathrm{C} 1 \mathrm{q}-\mathrm{Wnt} / \beta$-catenin signaling pathway and that RAS signaling and $\mathrm{Wnt} / \beta$-catenin signaling are hierarchically related in promoting the aging process (Fig. 1). We propose that RAS blockade reduces systemic and local levels of $\mathrm{C1q}$ through inhibiting $\mathrm{C1q}$ synthesis in infiltrated macrophages and thereby enhances proliferation and differentiation of satellite cells, leading to promotion of skeletal muscle repair. Besides selectively inhibiting Ang II-induced activation of $\mathrm{AT}_{1}$ receptor, $\mathrm{ARB}$ may enhance Ang II-induced activation of $\mathrm{AT}_{2}$ receptor [67]. Further studies will be required to elucidate whether $\mathrm{AT}_{2}$ receptor activation contributes to down-regulation of $\mathrm{C} 1 \mathrm{q}-\mathrm{Wnt} / \beta$-catenin signaling and protection against aging.

\section{Conclusions}

RAS is profoundly involved in the progression of various aging-related diseases and the promotion of the aging process. RAS blockade has been shown to protect against aging-related deleterious effects and promote longevity. We have recently shown that this anti-aging effect of RAS blockade was mediated by down-regulation of agingpromoting $\mathrm{Clq}$-Wnt/ $\beta$-catenin signaling pathway, suggesting the hierarchical relationship between RAS signaling and Wnt signaling in promoting aging-related phenotypes. It is a matter of interest whether blocking RAS signaling or $\mathrm{C} 1 \mathrm{q}-\mathrm{Wnt} / \mathrm{\beta}$-catenin signaling could prevent geriatric frailty and prolong life span in humans. It remains to be elucidated how RAS signaling induces $\mathrm{Clq}$ expression in macrophages during the aging process. Further investigations of the relationship between RAS signaling and $\mathrm{Clq}-\mathrm{Wnt} / \beta$-catenin signaling will provide insights into the mechanisms responsible for aging-related functional decline of multiple organs and open up a path toward the development of novel therapeutics against aging-related diseases.

\footnotetext{
Abbreviations

ACE, angiotensin-converting enzyme; Ang, angiotensin; ARB, angiotensin II type 1 receptor blocker; $A T_{1}$, angiotensin II type 1; LRP, low-density lipoprotein receptor-related protein; MLP, muscle LIM protein; $N A D(P) H$, nicotinamide adenine dinucleotide/nicotinamide adenine dinucleotide phosphate; NAD ${ }^{+}$, nicotinamide adenine dinucleotide; RAS, renin-angiotensin system; ROS, reactive oxygen species; SIRT, sirtuin; TGF- $\beta$, transforming growth factor- $\beta$.
}

\section{Funding}

This work was supported in part by grants from the Japan Society for the Promotion of Science (KAKENHI 26670395 to HA and AMED-CREST, Japan Agency for Medical Research and Development to HA and IK) and Health and Labor Sciences Research Grants (to HA and IK).

\section{Authors' contributions}

TK and HA wrote the manuscript, and JS and IK helped to draft the manuscript. All authors read and approved the final manuscript.

\section{Competing interests}

HA has received trust research/joint research funding from Shionogi \& Co., Ltd., and research funding from Takeda Pharmaceutical Co., Ltd., Daiichi Sankyo Co., Ltd., and Nippon Boehringer Ingelheim Co., Ltd. JS has received research funding from Nippon Boehringer Ingelheim Co., Ltd. IK has received research funding from Astellas Pharma Inc., Daiichi Sankyo Co., Ltd., Nippon Boehringer Ingelheim Co., Ltd., and Takeda Pharmaceutical Co., Ltd., and has affiliations with endowed department sponsored by Shionogi \& Co., Ltd.

\section{Author details}

${ }^{1}$ Department of Cardiovascular Medicine, Graduate School of Medicine, The University of Tokyo, 7-3-1 Hongo, Bunkyo-ku, Tokyo 113-8655, Japan. ${ }^{2}$ Department of Advanced Clinical Science and Therapeutics, Graduate School of Medicine, The University of Tokyo, Bunkyo-ku, Tokyo 113-8655, Japan. ${ }^{3}$ AMED-CREST, Japan Agency for Medical Research and Development, Chiyoda-ku, Tokyo 100-0004, Japan.

Received: 19 March 2016 Accepted: 18 May 2016

Published online: 09 August 2016

\section{References}

1. Akazawa H, Yano M, Yabumoto C, Kudo-Sakamoto Y, Komuro I. Angiotensin II type 1 and type 2 receptor-induced cell signaling. Curr Pharm Des. 2013; 19:2988-95

2. Zou Y, Akazawa H, Qin Y, Sano M, Takano H, Minamino T, et al. Mechanical stress activates angiotensin II type 1 receptor without the involvement of angiotensin II. Nat Cell Biol. 2004;6:499-506

3. Yasuda N, Miura S, Akazawa H, Tanaka T, Qin Y, Kiya Y, et al. Conformational switch of angiotensin II type 1 receptor underlying mechanical stressinduced activation. EMBO Rep. 2008;9:179-86.

4. Niimura F, Labosky PA, Kakuchi J, Okubo S, Yoshida H, Oikawa T, et al. Gene targeting in mice reveals a requirement for angiotensin in the development and maintenance of kidney morphology and growth factor regulation. J Clin Invest. 1995;96:2947-54.

5. Oliverio MI, Kim HS, Ito M, Le T, Audoly L, Best CF, et al. Reduced growth, abnormal kidney structure, and type 2 (AT2) angiotensin receptor-mediated blood pressure regulation in mice lacking both AT1A and AT1B receptors for angiotensin II. Proc Natl Acad Sci USA. 1998;95:15496-501.

6. Tsuchida S, Matsusaka T, Chen X, Okubo S, Niimura F, Nishimura H, et al. Murine double nullizygotes of the angiotensin type $1 \mathrm{~A}$ and $1 \mathrm{~B}$ receptor genes duplicate severe abnormal phenotypes of angiotensinogen nullizygotes. J Clin Invest. 1998;101:755-60.

7. Cooper WO, Hernandez-Diaz S, Arbogast PG, Dudley JA, Dyer S, Gideon PS, et al. Major congenital malformations after first-trimester exposure to ACE inhibitors. N Engl J Med. 2006;354:2443-51.

8. Hunyady L, Catt KJ. Pleiotropic AT1 receptor signaling pathways mediating physiological and pathogenic actions of angiotensin II. Mol Endocrinol. 2006;20:953-70.

9. Kamo T, Akazawa H, Komuro I. Pleiotropic effects of angiotensin II receptor signaling in cardiovascular homeostasis and aging. Int Heart J. 2015:56:249-54.

10. Benigni A, Corna D, Zoja C, Sonzogni A, Latini R, Salio M, et al. Disruption of the Ang II type 1 receptor promotes longevity in mice. J Clin Invest. 2009; 119:524-30.

11. Jiang $F$, Yang J, Zhang $Y$, Dong $M$, Wang S, Zhang $Q$, et al. Angiotensin-converting enzyme 2 and angiotensin 1-7: novel therapeutic targets. Nat Rev Cardiol. 2014;11:413-26.

12. Clevers H. Wnt/B-catenin signaling in development and disease. Cell. 2006; 127:469-80. 
13. Brack AS, Conboy MJ, Roy S, Lee M, Kuo CJ, Keller C, et al. Increased Wnt signaling during aging alters muscle stem cell fate and increases fibrosis. Science. 2007;317:807-10.

14. Naito AT, Sumida T, Nomura S, Liu ML, Higo T, Nakagawa A, et al. Complement $\mathrm{C} 1 \mathrm{q}$ activates canonical Wnt signaling and promotes aging-related phenotypes. Cell. 2012;149:1298-313.

15. Yabumoto C, Akazawa H, Yamamoto R, Yano M, Kudo-Sakamoto Y, Sumida $T$, et al. Angiotensin II receptor blockade promotes repair of skeletal muscle through down-regulation of aging-promoting C1q expression. Sci Rep. 2015:5:14453.

16. Dzau V. The cardiovascular continuum and renin-angiotensin-aldosterone system blockade. J Hypertens Suppl. 2005;23:S9-17.

17. Folkow B. Physiological aspects of primary hypertension. Physiol Rev. 1982; 62:347-504.

18. Julius S, Nesbitt SD, Egan BM, Weber MA, Michelson EL, Kaciroti N, et al. Feasibility of treating prehypertension with an angiotensin-receptor blocker. N Engl J Med. 2006;354:1685-97.

19. Linz W, Jessen T, Becker RH, Schölkens BA, Wiemer G. Long-term ACE inhibition doubles lifespan of hypertensive rats. Circulation. 1997;96:3164-72

20. Linz W, Heitsch H, Schölkens BA, Wiemer G. Long-term angiotensin II type 1 receptor blockade with fonsartan doubles lifespan of hypertensive rats. Hypertension. 2000;35:908-13.

21. Garrido AM, Griendling KK. NADPH oxidases and angiotensin II receptor signaling. Mol Cell Endocrinol. 2009;302:148-58.

22. Ferrario CM, Strawn WB. Role of the renin-angiotensin-aldosterone system and proinflammatory mediators in cardiovascular disease. Am J Cardiol. 2006;98: $121-8$.

23. Koh KK, Oh PC, Quon MJ. Does reversal of oxidative stress and inflammation provide vascular protection? Cardiovasc Res. 2009;81:649-59.

24. Schmieder RE, Hilgers KF, Schlaich MP, Schmidt BM. Renin-angiotensin system and cardiovascular risk. Lancet. 2007;369:1208-19.

25. Kim S, Iwao H. Molecular and cellular mechanisms of angiotensin IImediated cardiovascular and renal diseases. Pharmacol Rev. 2000;52:11-34

26. Dostal DE, Baker KM. Angiotensin II stimulation of left ventricular hypertrophy in adult rat heart. Mediation by the AT1 receptor. Am J Hypertens. 1992;5:276-80.

27. Hein L, Stevens ME, Barsh GS, Pratt RE, Kobilka BK, Dzau VJ. Overexpression of angiotensin AT1 receptor transgene in the mouse myocardium produces a lethal phenotype associated with myocyte hyperplasia and heart block. Proc Natl Acad Sci USA. 1997;94:6391-6.

28. Paradis P, Dali-Youcef N, Paradis FW, Thibault G, Nemer M. Overexpression of angiotensin II type I receptor in cardiomyocytes induces cardiac hypertrophy and remodeling. Proc Natl Acad Sci USA. 2000;97:931-6.

29. Harada K, Sugaya T, Murakami K, Yazaki Y, Komuro I. Angiotensin II type 1A receptor knockout mice display less left ventricular remodeling and improved survival after myocardial infarction. Circulation. 1999;100:2093-9.

30. Toko H, Oka T, Zou Y, Sakamoto M, Mizukami M, Sano M, et al. Angiotensin II type 1a receptor mediates doxorubicin-induced cardiomyopathy. Hypertens Res. 2002;25:597-603.

31. Yamamoto R, Akazawa H, Ito K, Toko H, Sano M, Yasuda N, et al. Angiotensin II type 1a receptor signals are involved in the progression of heart failure in MLP-deficient mice. Circ J. 2007:71:1958-64.

32. Klingbeil AU, Schneider M, Martus P, Messerli FH, Schmieder RE. A meta-analysis of the effects of treatment on left ventricular mass in essential hypertension. Am J Med. 2003;115:41-6.

33. Mielniczuk L, Stevenson LW. Angiotensin-converting enzyme inhibitors and angiotensin II type I receptor blockers in the management of congestive heart failure patients: what have we learned from recent clinical trials? Curr Opin Cardiol. 2005;20:250-5.

34. Prasad A, Quyyumi AA. Renin-angiotensin system and angiotensin receptor blockers in the metabolic syndrome. Circulation. 2004;110:1507-12.

35. Velloso LA, Folli F, Sun XJ, White MF, Saad MJ, Kahn CR. Cross-talk between the insulin and angiotensin signaling systems. Proc Natl Acad Sci USA. 1996; 93:12490-5

36. Carlsson PO, Berne C, Jansson L. Angiotensin II and the endocrine pancreas: effects on islet blood flow and insulin secretion in rats. Diabetologia. 1998; 41:127-33.

37. Tikellis C, Wookey PJ, Candido R, Andrikopoulos S, Thomas MC, Cooper ME. Improved islet morphology after blockade of the renin-angiotensin system in the ZDF rat. Diabetes. 2004;53:989-97.
38. Abuissa H, Jones PG, Marso SP, O'Keefe Jr JH. Angiotensin-converting enzyme inhibitors or angiotensin receptor blockers for prevention of type 2 diabetes: a meta-analysis of randomized clinical trials. J Am Coll Cardiol. 2005:46:821-6.

39. Remuzzi G, Bertani T. Pathophysiology of progressive nephropathies. N Engl J Med. 1998:339:1448-56.

40. Remuzzi G, Perico N, Macia M, Ruggenenti P. The role of reninangiotensin-aldosterone system in the progression of chronic kidney disease. Kidney Int Suppl. 2005;68:S57-65.

41. Lewis EJ, Hunsicker LG, Clarke WR, Berl T, Pohl MA, Lewis JB, et al. Renoprotective effect of the angiotensin-receptor antagonist irbesartan in patients with nephropathy due to type 2 diabetes. N Engl J Med. 2001:345:851-60.

42. Brenner BM, Cooper ME, de Zeeuw D, Keane WF, Mitch WE, Parving HH, et al. Effects of losartan on renal and cardiovascular outcomes in patients with type 2 diabetes and nephropathy. N Engl J Med. 2001;345:861-9.

43. Wang J, Ho L, Chen L, Zhao Z, Zhao W, Qian X, et al. Valsartan lowers brain $\beta$-amyloid protein levels and improves spatial learning in a mouse model of Alzheimer disease. J Clin Invest. 2007;117:3393-402.

44. Shimizu H, Nakagami H, Osako MK, Hanayama R, Kunugiza Y, Kizawa T, et al. Angiotensin II accelerates osteoporosis by activating osteoclasts. FASEB J. 2008;22:2465-75.

45. Rejnmark L, Vestergaard P, Mosekilde L. Treatment with beta-blockers, ACE inhibitors, and calcium-channel blockers is associated with a reduced fracture risk: a nationwide case-control study. J Hypertens. 2006;24:581-9.

46. Fujimoto Y, Sasaki T, Tsuchida A, Chayama K. Angiotensin II type 1 receptor expression in human pancreatic cancer and growth inhibition by angiotensin II type 1 receptor antagonist. FEBS Lett. 2001;495:197-200.

47. Uemura H, Ishiguro H, Nakaigawa N, Nagashima Y, Miyoshi Y, Fujinami K, et al. Angiotensin II receptor blocker shows antiproliferative activity in prostate cancer cells: a possibility of tyrosine kinase inhibitor of growth factor. Mol Cancer Ther. 2003:2:1139-47.

48. Rhodes DR, Ateeq B, Cao Q, Tomlins SA, Mehra R, Laxman B, et al. AGTR1 overexpression defines a subset of breast cancer and confers sensitivity to losartan, an AGTR1 antagonist. Proc Natl Acad Sci USA. 2009;106:10284-9.

49. Egami K, Murohara T, Shimada T, Sasaki K, Shintani S, Sugaya T, et al. Role of host angiotensin II type 1 receptor in tumor angiogenesis and growth. J Clin Invest. 2003;112:67-75.

50. Cortez-Retamozo V, Etzrodt M, Newton A, Ryan R, Pucci F, Sio SW, et al. Angiotensin II drives the production of tumor-promoting macrophages. Immunity. 2013;38:296-308.

51. Ferder L, Inserra F, Romano L, Ercole L, Pszenny V. Effects of angiotensinconverting enzyme inhibition on mitochondrial number in the aging mouse. Am J Physiol. 1993;265:C15-8.

52. Basso N, Cini R, Pietrelli A, Ferder L, Terragno NA, Inserra F. Protective effect of long-term angiotensin II inhibition. Am J Physiol Heart Circ Physiol. 2007; 293:H1351-8.

53. Ferder LF, Inserra F, Basso N. Advances in our understanding of aging: role of the renin-angiotensin system. Curr Opin Pharmacol. 2002;2:189-94.

54. Finkel T, Holbrook NJ. Oxidants, oxidative stress and the biology of ageing. Nature. 2000;408:239-47.

55. Ferder L, Romano LA, Ercole LB, Stella I, Inserra F. Biomolecular changes in the aging myocardium: the effect of enalapril. Am J Hypertens. 1998;11: 1297-304.

56. Yang $H$, Yang $T$, Baur JA, Perez E, Matsui T, Carmona JJ, et al. Nutrient-sensitive mitochondrial NAD ${ }^{+}$levels dictate cell survival. Cell. 2007;130:1095-107.

57. Onder G, Penninx BW, Balkrishnan R, Fried LP, Chaves PH, Williamson $J$, et al. Relation between use of angiotensin-converting enzyme inhibitors and muscle strength and physical function in older women: an observational study. Lancet. 2002;359:926-30.

58. Di Bari M, van de Poll-Franse LV, Onder G, Kritchevsky SB, Newman A, Harris $\mathrm{TB}$, et al. Antihypertensive medications and differences in muscle mass in older persons: the Health, Aging and Body Composition Study. J Am Geriatr Soc. 2004;52:961-6.

59. Burks TN, Andres-Mateos E, Marx R, Mejias R, Van Erp C, Simmers JL, et al. Losartan restores skeletal muscle remodeling and protects against disuse atrophy in sarcopenia. Sci Transl Med. 2011:3:82ra37.

60. Bedair HS, Karthikeyan T, Quintero A, Li Y, Huard J. Angiotensin II receptor blockade administered after injury improves muscle regeneration and decreases fibrosis in normal skeletal muscle. Am J Sports Med. 2008;36:1548-54. 
61. Cohn RD, van Erp C, Habashi JP, Soleimani AA, Klein EC, Lisi MT, et al. Angiotensin II type 1 receptor blockade attenuates TGF- $\beta$-induced failure of muscle regeneration in multiple myopathic states. Nat Med. 2007;13:204-10.

62. Yoshida T, Galvez S, Tiwari S, Rezk BM, Semprun-Prieto L, Higashi Y, et al. Angiotensin II inhibits satellite cell proliferation and prevents skeletal muscle regeneration. J Biol Chem. 2013;288:23823-32.

63. MacDonald BT, Tamai K, He X. Wnt/ $\beta$-catenin signaling: components, mechanisms, and diseases. Dev Cell. 2009;17:9-26.

64. Liu H, Fergusson MM, Castilho RM, Liu J, Cao L, Chen J, et al. Augmented Wnt signaling in a mammalian model of accelerated aging. Science. 2007; 317:803-6.

65. Petry F, Botto M, Holtappels R, Walport MJ, Loos M. Reconstitution of the complement function in C1q-deficient (C1qa-/-) mice with wild-type bone marrow cells. J Immunol. 2001;167:4033-7.

66. Sumida T, Naito AT, Nomura S, Nakagawa A, Higo T, Hashimoto A, et al. Complement C1q-induced activation of $\beta$-catenin signalling causes hypertensive arterial remodelling. Nat Commun. 2015:6:6241.

67. Wu L, Iwai M, Nakagami H, Li Z, Chen R, Suzuki J, et al. Roles of angiotensin II type 2 receptor stimulation associated with selective angiotensin II type 1 receptor blockade with valsartan in the improvement of inflammation-induced vascular injury. Circulation. 2001;104:2716-21.

\section{Submit your next manuscript to BioMed Central} and we will help you at every step:

- We accept pre-submission inquiries

- Our selector tool helps you to find the most relevant journal

- We provide round the clock customer support

- Convenient online submission

- Thorough peer review

- Inclusion in PubMed and all major indexing services

- Maximum visibility for your research

Submit your manuscript at www.biomedcentral.com/submit 